\title{
Design and Analysis of Ultra-wideband Micro Strip Patch Antenna with Notch Band Characteristics
}

\author{
Omprakash $\operatorname{Kumar}^{1, a}$ and Surender Kumar Soni ${ }^{1}$ \\ ${ }^{1}$ National Institute of Technology, ECE Department, Hamirpur, Himachal Pradesh, India
}

\begin{abstract}
A new design of ultra-wideband (UWB) micro strip patch antenna with notch band characteristic for wireless local area network (WLAN) application is presented in this paper. The proposed antenna consists of a rectangular patch with a partial ground plane that is fed by $50 \Omega$ micro strip line. A notch band function is created by inserting overlapped one $\mathrm{U}$-shape and one $\mathrm{C}$-shape slot on the radiator patch, added additional patch to the ground plane side and slit in truncated ground plane. The proposed antenna potentially minimized frequency interference between WLAN and UWB system. This antenna with the size of $26 \mathrm{~mm} \times 32 \mathrm{~mm}(\mathrm{~W} \times \mathrm{L})$ and the simulated results show that the antenna can operate over the frequency band between 3.1 and $10.45 \mathrm{GHz}$ for voltage standing wave ratio $($ VSWR $)>2$ with band notch 5.06-5.825 GHz. Besides in the working band, the antenna shows good radiation pattern in the H-plane and the E-plane and has good time domain characteristic.
\end{abstract}

\section{Introduction}

Ultra-wideband technology has become most promising technology since FCC (Federal Communication commission) approved the 3.1-10.6 GHz band for unlicensed radio frequency applications. It has the advantages of low power consumption, high data transmission, less complexity, low cost etc. However, the design of compact, low profile and efficient antennas for UWB applications is still a major challenge and micro strip antennas are mainly used in aircraft, spacecraft, satellite and missile applications where high performance, ease of installation, low cost and small size are major constraints. Wireless local area network (WLAN) is operating in the 5.15-5.825 GHz band. The interferences caused by this narrowband can be reduced by using spatial filters but this approach requires too much space and expansive. The UWB antenna with band notched characteristic is the best option to mitigate the interference between narrowband (WLAN) and UWB system.

In this paper, a notch band function is created by inserting overlapped one u-shaped and one c-shaped slot on the radiator patch, added additional patch to the ground plane side and slit in truncated ground plane. The proposed antenna completely rejected the entire 5.06$5.825 \mathrm{GHz}$ frequency band achieved by varying the position of micro strip feed line, size of additional patch to the ground plane and depth of the slit in truncated ground plane, though the desired notch band for WLAN is $5.15-5.825 \mathrm{GHz}$. So, any useful information contained in the frequency band of 5.07-5.14 GHz will be lost. With a compact size of $26 \mathrm{~mm} \times 32 \mathrm{~mm}$, the $-10 \mathrm{~dB}$ impedance bandwidth of the proposed antenna is sufficient to cover the entire ultra-wideband frequency with notch band for WLAN.

Table 1. Comparison between proposed and recently reported band notch UWB antennas.

\begin{tabular}{|c|c|c|}
\hline Band notch UWB antennas & $\begin{array}{c}\text { Dimensions } \\
(\mathbf{W} \times \mathbf{L}) \\
(\mathbf{m m} \times \mathbf{m m})\end{array}$ & $\begin{array}{c}\text { Notched band } \\
\mathbf{( G H z}-\mathbf{G H z})\end{array}$ \\
\hline $\begin{array}{c}\text { Compact ultra-wideband } \\
\text { rectangular aperture antenna } \\
\text { and band notched design.[1] }\end{array}$ & $35 \times 35$ & $5-6$ \\
\hline $\begin{array}{c}\text { Compact ultra-wideband } \\
\text { antenna with band notched } \\
\text { using ground stubs.[2] }\end{array}$ & $30 \times 39$ & $5.15-5.825$ \\
\hline $\begin{array}{c}\text { Compact monopole antenna } \\
\text { with band notched } \\
\text { characteristics.[3] }\end{array}$ & $30 \times 35$ & $5.12-6.08$ \\
\hline $\begin{array}{c}\text { Compact band notched UWB } \\
\text { printed antenna using inverted } \\
\text { L-slit.[4] }\end{array}$ & $30 \times 36$ & $4.85-6.04$ \\
\hline $\begin{array}{c}\text { An omnidirectional and band } \\
\text { notched UWB antenna on } \\
\text { double substrate crossing.[5] }\end{array}$ & $3 \mathrm{D}$ profile & $5.1-6.2$ \\
\hline $\begin{array}{c}\text { Compact planer UWB } \\
\text { antenna with band notch } \\
\text { characteristic.[6] }\end{array}$ & $26 \times 24$ & $5.1-5.95$ \\
\hline Proposed antenna & $\mathbf{2 6} \times \mathbf{3 2}$ & $\mathbf{5 . 0 6}-\mathbf{5 . 8 2 5}$ \\
\hline
\end{tabular}

Table 1, shows the comparison between proposed and recently reported band notch UWB antennas from

\footnotetext{
$\overline{{ }^{a} \text { Omprakash Kumar: opkumar57@gmail.com }}$
} 
where it is clear that the proposed antenna has compact profile and desired notch band compare to others.

In this paper, section 2 presents the geometry of the proposed antenna. Section 3 presents the result of some important features of proposed antenna such as return loss, VSWR and radiation patterns. Section 4 presents the conclusion.

\section{Antenna design and analysis}

The proposed antenna is simulated using transient solver in Computer simulation technology (CST) microwave studio. Figure 1 shows the geometry and configuration of proposed notched band UWB antenna, which is designed on FR4 substrate with a thickness of $1.6 \mathrm{~mm}$, relative permittivity of 4.3 and loss tangent of 0.03 . The proposed antenna composed of a rectangular patch is fed by a micro strip line and printed on FR4 substrate having dimension of $26 \mathrm{~mm} \times 32 \mathrm{~mm}$. A notch band function is created by inserting overlapped one $\mathrm{u}$-shaped and one cshaped slot on the radiator patch, added additional patch to the ground plane side and slit in truncate ground plane. To match $50 \Omega$ characteristic impedance micro strip feed line is designed and enhanced by adjusting the dimension of the feeding structure and patch size. The micro strip feed line is having fixed length (LM) $13.5 \mathrm{~mm}$ and width (WM) $2.2 \mathrm{~mm}$ and positioned at $2.7 \mathrm{~mm}$ far from symmetrical position.

To design a micro strip patch over FR4 substrate, U-shaped and C-shaped slot in patch has done by the help of some mathematical calculation as follows. Here three essential parameters are required for proposed antenna design, resonant frequency $f_{0}$ selected in the frequency range of 3.1-10.6 GHz, height of the substrate $h=1.6 \mathrm{~mm}$ and dielectric constant of the substrate $\varepsilon_{r}=4.3$. The dimensions of the patch antenna along its length extended on each side by a distance of, where $h$ is the height of substrate and $\varepsilon_{\text {reff }}$ is the effective dielectric constant

$$
\Delta L=0.412 h \frac{\left(\varepsilon_{\text {reff }}+0.3\right)\left(\frac{W}{h}+0.264\right)}{\left(\varepsilon_{\text {reff }}-0.258\right)\left(\frac{W}{h}+0.8\right)}
$$

Slot thickness is calculated as

$$
S=\frac{\lambda_{O}}{60}
$$

Where operational wavelength is

$$
\lambda_{o}=\frac{c}{f_{o}}
$$

Effective length of patch antenna is calculated as

$$
\text { Leff }=L+2 \Delta L
$$

For a given resonant frequency, Effective length is given as

$$
\text { Leff }=\frac{c}{2 f_{o} \sqrt{\varepsilon_{r e f f}}}
$$

Effective dielectric constant of patch antenna is given as

$$
\varepsilon_{\text {reff }}=\frac{\varepsilon_{r}+1}{2}+\frac{\varepsilon_{r}-1}{2}\left[1+12 \frac{h}{W}\right]^{-\frac{1}{2}}(6)
$$

The width of the patch antenna is given as

$$
W=\frac{c}{2 f_{o} \sqrt{\frac{\left(\varepsilon_{r}+1\right)}{2}}}
$$

Length and Width of slot is given as

$$
L s=W S=\frac{c}{6.2 \sqrt{\varepsilon_{\text {reff }}}}-\frac{3}{2}(L+\Delta L+S)
$$

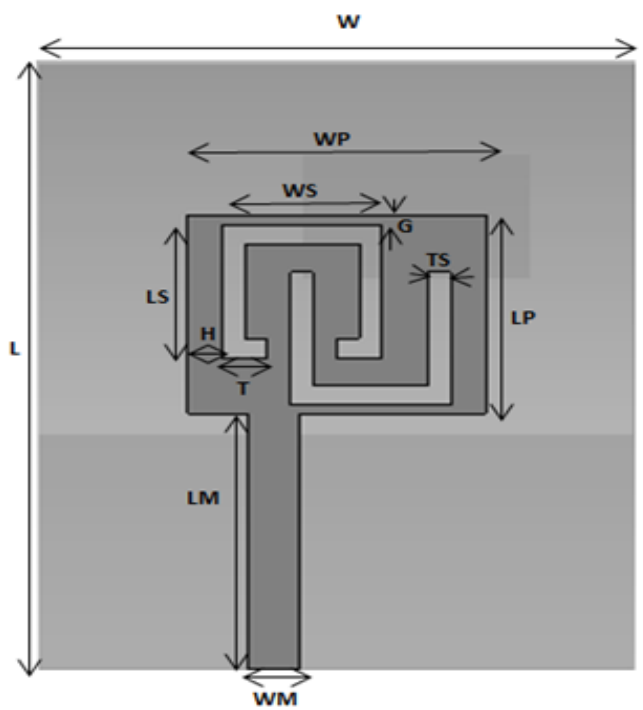

(a) Top view

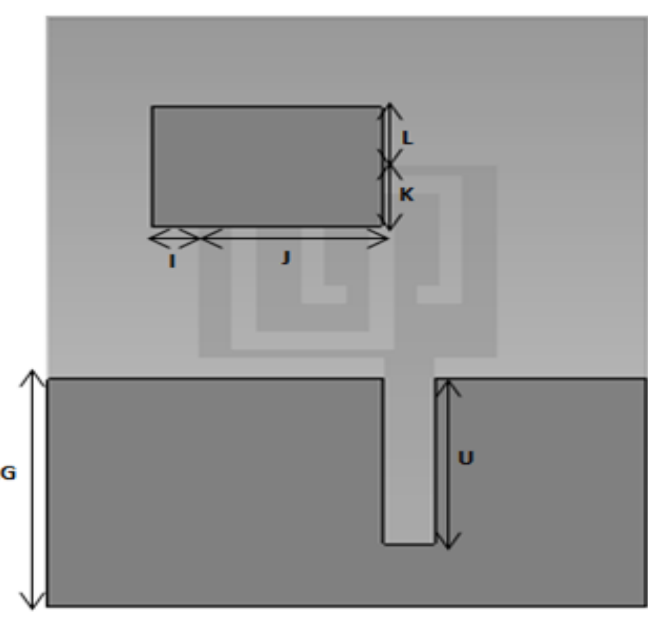

(b) Bottom view

Figure 1. (a) Proposed antenna with C-slot and U-slot (b) Additional patch and additional strip in truncated ground plane. 
Table 2. Final dimensions of the proposed antenna.

\begin{tabular}{|l|l|l|l|l|l|l|l|l|l|}
\hline $\begin{array}{l}\text { Para- } \\
\text { meter }\end{array}$ & L & G & J & K & L & LS & LM & WM & TS \\
\hline $\begin{array}{l}\text { Valu } \\
\text { (m } \\
\text { m) }\end{array}$ & 32 & $\begin{array}{l}0 . \\
5\end{array}$ & 5 & $\begin{array}{l}3 . \\
5\end{array}$ & 3 & 7 & $\begin{array}{l}13 . \\
5\end{array}$ & 2.2 & 1 \\
\hline $\begin{array}{l}\text { Para- } \\
\text { meter }\end{array}$ & W & H & T & U & I & LG & WP & LP & WS \\
\hline $\begin{array}{l}\text { Valu } \\
\text { (mm) } \\
\text { (mm) }\end{array}$ & 26 & $\begin{array}{l}1 . \\
5\end{array}$ & 2 & 9 & 2 & 12. & 13 & 10.5 & 7 \\
\hline
\end{tabular}

\section{Simulation results}

Fig. 2 shows the simulated return loss S1, 1 against frequency of the antenna with the help of CST microwave studio. As observed, the simulated impedance bandwidth with $10 \mathrm{~dB}$ return loss for the proposed antenna is from $3.1-10.45 \mathrm{GHz}$, notching the frequency band of about 5.06-5.825 GHz. So, it can mitigate interference between narrowband (WLAN) and UWB system.

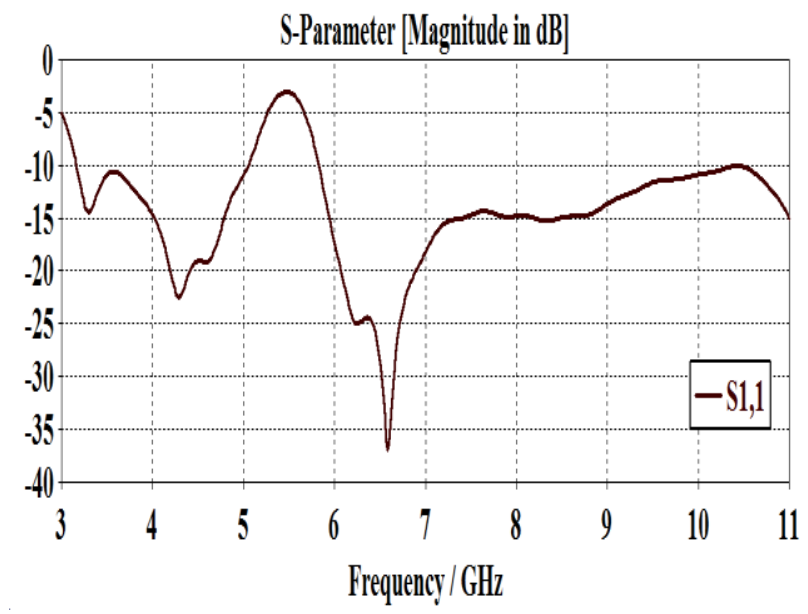

Figure 2. Simulated S1, 1 in dB for the proposed antenna.

Fig. 3 shows the proposed antenna return loss for varying the feed line positions. The impedance bandwidth is sensitive to the feed line position and when the feed line shifts from $\mathrm{d}=2.7 \mathrm{~mm}$ away from the symmetrical position. There are three simulated result as shown in fig. 3 , due to increase and decrease the feed line position 0.5 $\mathrm{mm}$ away from the $\mathrm{d}=2.7 \mathrm{~mm}$. In this figure $\mathrm{S} 1,1$ (1) shows desired feed line position of proposed antenna and S1, 1(2) represents left shift from $0.5 \mathrm{~mm} \mathrm{S1,} \mathrm{1(3)}$ represents right shift from $0.5 \mathrm{~mm}$.

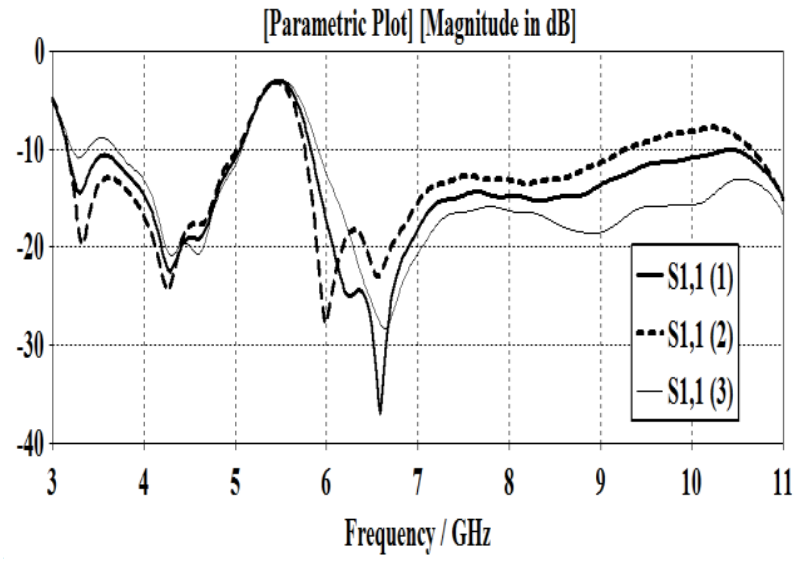

Figure 3. Return loss due to different positions of feed line.

The impedance bandwidth is very sensitive to the length of truncated ground plane and when truncated ground length shifts from $\mathrm{LG}=12.6 \mathrm{~mm}$. Here $\mathrm{LG} 1$ is the distance between origins of proposed antenna to LG. The electric current is greatly affected by the shape and size of truncated ground plane system. There are three simulated result in fig. 4 , due to increase and decrease 0.5 $\mathrm{mm}$ length of truncated ground plane from $\mathrm{LG}=12.6 \mathrm{~mm}$.

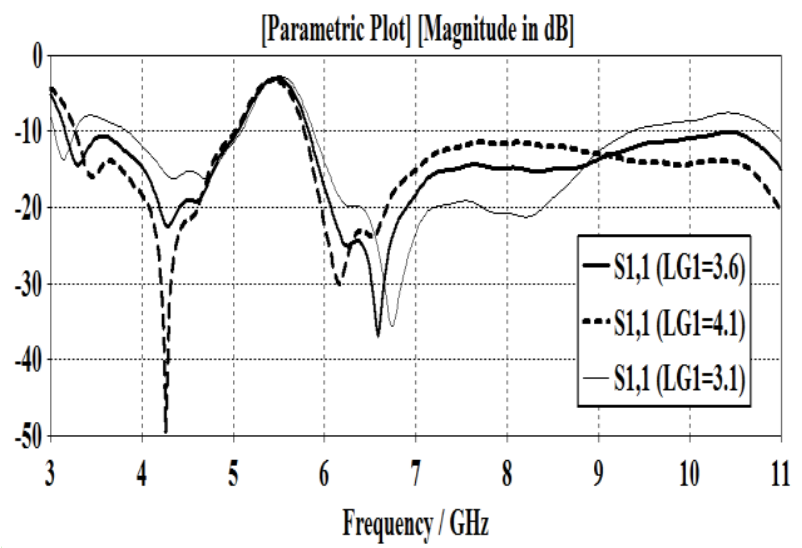

Figure 4. Return loss due to different ground length.

Fig. 5 shows the simulated voltage standing wave ratio (VSWR) for the proposed antenna design. It shows that the desired notch band can be obtained by varying the parameter of proposed antenna. The notch band shows VSWR $>2$ while it maintains good impedance matching at other frequencies in UWB band.

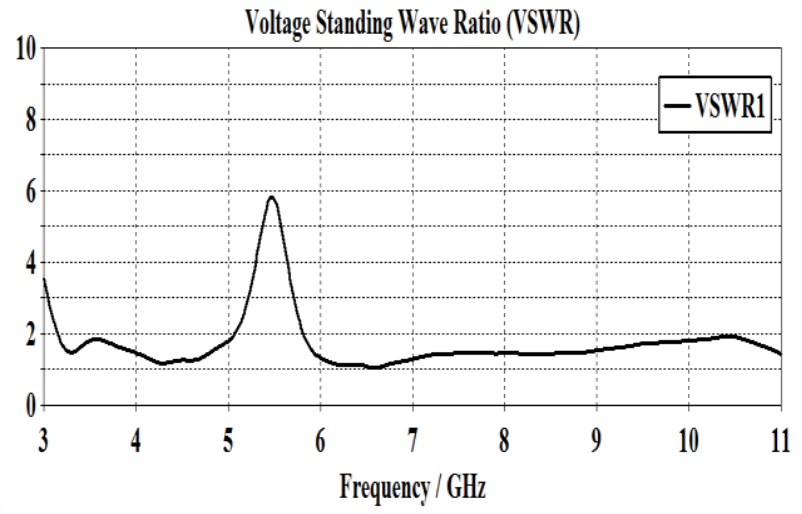

Figure 5. Simulated VSWR of proposed antenna. 
The simulated radiation patterns of proposed antenna for three different frequencies $3.91,5.5$ and $7.5 \mathrm{GHz}$ in the E-plane and H-plane are shown in fig. 6. The radiation patterns in the H-plane are quite omnidirectional as expected and in the E-plane like a small dipole leading to bidirectional patterns.
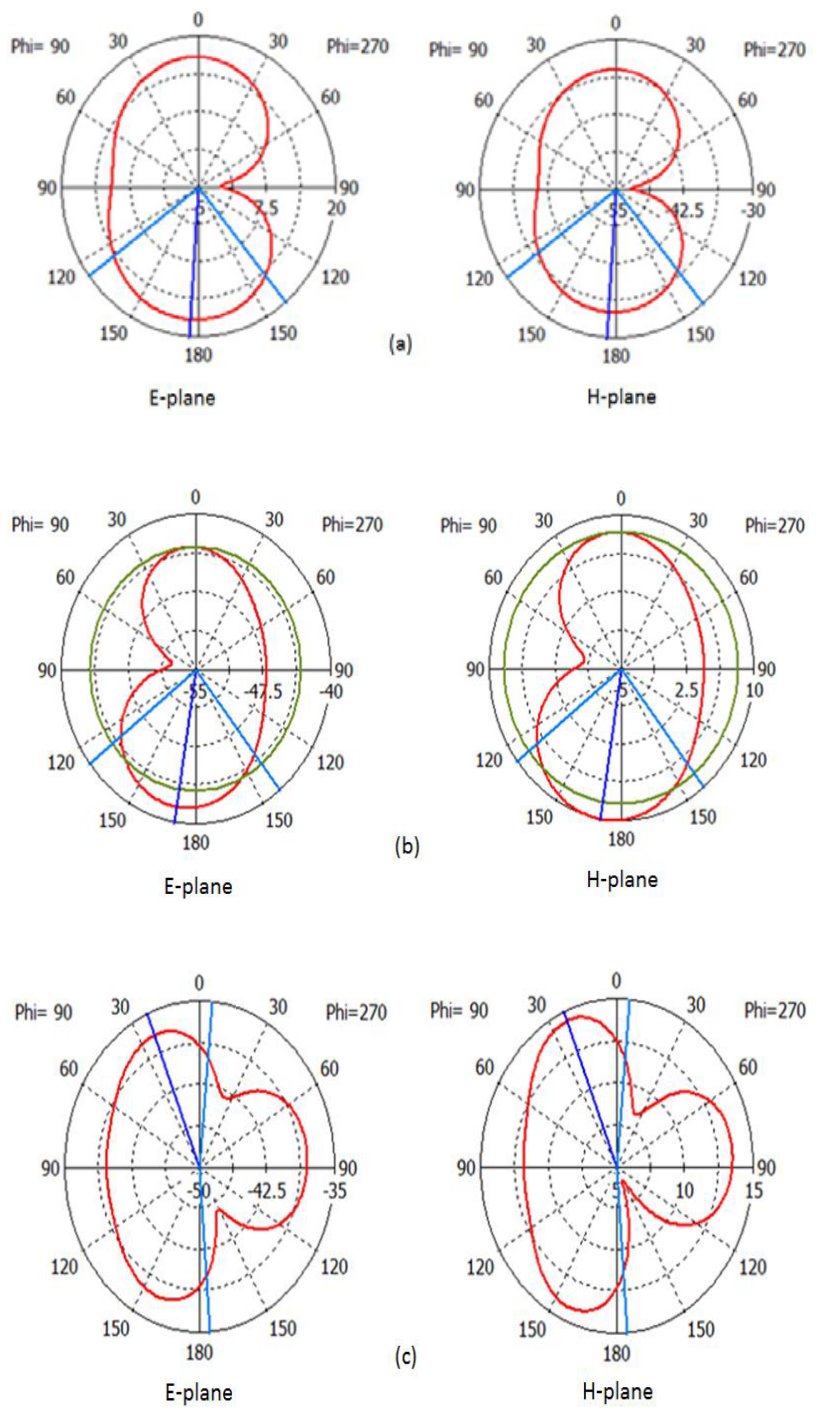

Figure 6. Radiation patterns for proposed antenna at; (a) 3.91 GHz (b) $5.5 \mathrm{GHz}$ (c) $7.5 \mathrm{GHz}$.

\section{Conclusion}

The simulations were carried out using CST microwave studio in time domain. This work presents a simple structure of an ultra-wideband microstrip patch antenna with band notched characteristic. The proposed antenna operates in 3.1-10.45 GHz and notched band is in 5.06$5.825 \mathrm{GHz}$ for WLAN application. Overlapping one Cplane and one U-plane slots in the radiating patch, slit in truncated ground plane and additional patch in bottom side are introduced in this paper to create a notched band in order to mitigate interferences between narrowband system (WLAN) and UWB system and make more efficient notched band UWB patch antenna. The applications of the proposed antenna are in the medical imaging, wireless communication, radars and special in ground penetrating radar (GPR). The proposed antenna is easily fabricated with $\mathrm{RF} /$ microwave circuits with low cost. In this paper main concern is to get notched band between $5.15-5.825 \mathrm{GHz}$ as much as possible because any other frequency out of this desired notch band is rejected so some useful information will be lost.

\section{References}

1. Lin, Y.-C. and K.-J. Hung, "Compact ultra-wideband rectangular aperture antenna and band-notched designs," IEEE Transactions on Antennas and Propagation, Vol. 54, No. 11, 3075-3081, 2006.

2. Wang, Y. F., S. W. Cheung, and T. I. Yuk, "Compact ultra-wideband antennas with single bandnotched characteristics using simple ground stubs," Microwave and Optical Technology Letters, Vol. 53, No. 3, 523-529, 2011.

3. Liu, H.-W., C.-H. Ku, T.-S. Wang, and C.-F. Yang, "Compact monopole antenna with band-notched characteristic for UWB applications," IEEE Antennas and Wireless Propagation Letters, Vol. 9, 397-400, 2010.

4. Yoon, C., W.-J. Lee, W.-S. Kim, H.-C. Lee, and H.D. Park, "Compact band-notched ultra-wideband printed antenna using inverted L-slit," Microwave and Optical Technology Letters, Vol. 54, No. 1, 143144, 2012.

5. Liao, Z., F. Zhang, G. Xie, W. Zhai, and L. Chen, "An omnidirectional and band-notched ultra wideband antenna on double substrates crossing," Progress In Electromagnetics Research C, Vol. 22, 231-240, 2011.

6. R. Azim and M. T. Islam, 'Compact planar UWB antenna with band notch characteristics for WLAN and DSRC,' Progress in Electromagnetics Research, Vol. 133, 391-406, 2013. 